\title{
ОРГАН ДОЗНАНИЯ КАК СУБЬЕКТ ПРОЦЕССУАЛЬНОЙ ПРОВЕРКИ
}

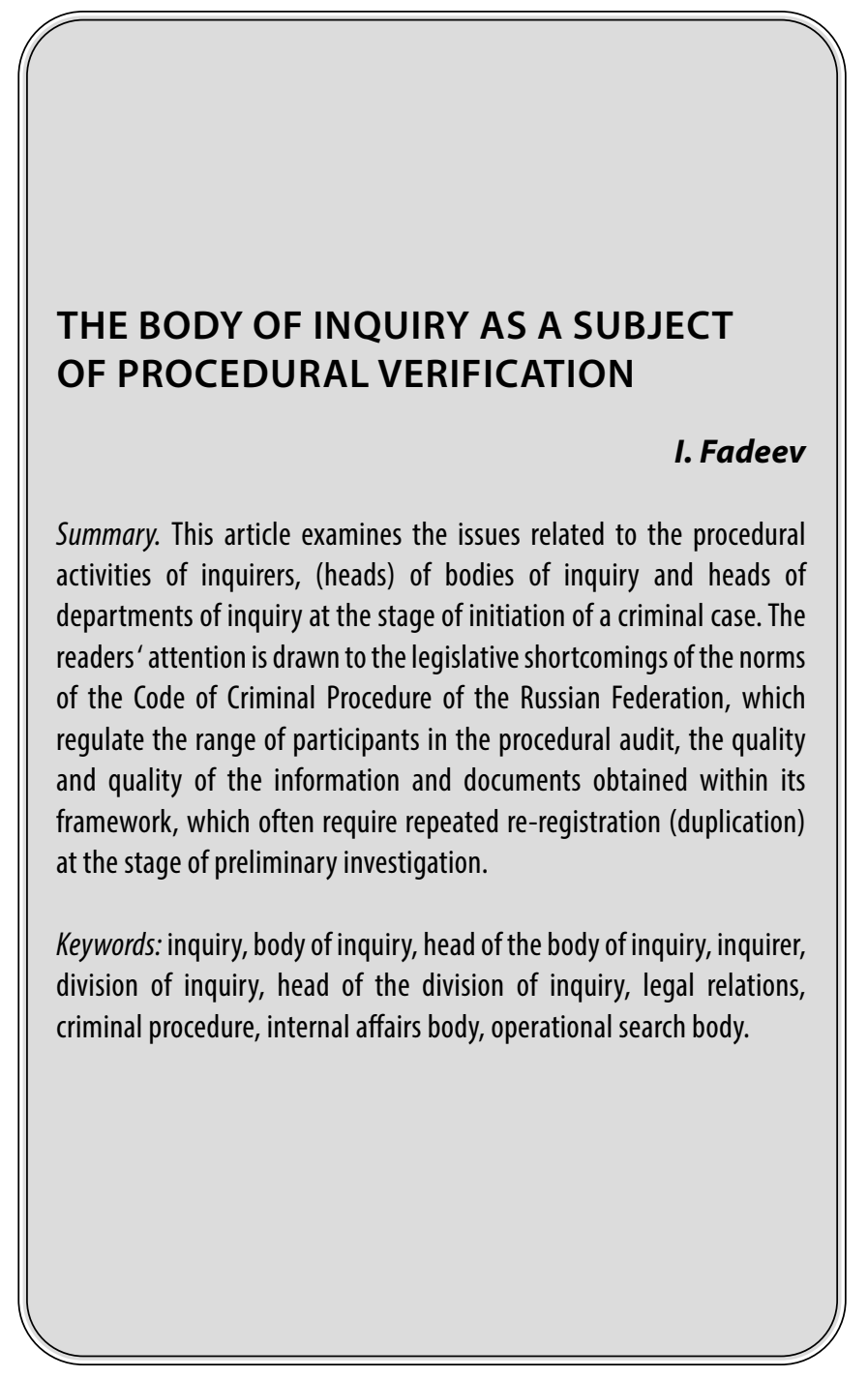

$\mathbf{H}$ овейшие изменения, внесенные в УПК РФ, заметно осложнили правовой режим процессуальной проверки сообщения о преступлениях. Не вдаваясь в подробности относительно поводов к возбуждению уголовного дела, которые логичнее было бы называть поводами к процессуальной проверке, заострим здесь внимание лишь на содержании ч. 2 ст. 140 УПК РФ, определяющей, что основанием для возбуждения уголовного дела является наличие достаточных 1 данных, указывающих на признаки преступления.

В представленной редакции, как нетрудно убедиться, законодатель сглаживает очевидную антитезу: достаточность данных - признаки преступления.

Здесь и далее курсив автора.

\author{
Фадеев Илья Александрович \\ К.ю.н., майор поличии, старший преподаватель, \\ Академия управления, \\ Академия управления МВД России \\ llya-fadeev@yandex.ru
}

Аннотация. В настоящей статье исследуются вопросы, касающиеся процессуальной деятельности дознавателей, (начальников) органов дознания и руководителей подразделений дознания в стадии возбуждения уголовного дела. Внимание читателей обращается на законодательную недоработку норм УПК РФ, регламентирующих круг участников процессуальной проверки, качество и статус получаемых в её рамках сведений и документов, требующих нередко повторного переоформления (дублирования) в (тадии предварительного расследования.

Ключевые слова: дознание, орган дознания, начальник органа дознания, дознаватель, подразделение дознания, руководитель подразделения дознания, правоотношения, уголовный процесс, орган внутренних дел, оперативно-розыскной орган.

Такой приём вызывает возражения, поскольку в единую юридическую формулу включается два взаимоисключающих тезиса. С одной стороны, используется некорректное выражение «достаточные данные», намекающее на некоторую долю их информационной насыщенности, а с другой - словосочетание «признаки преступления», подчеркивающее их дефицит.

Не менее занимательны употребляемые на равных терминологические выражения «признаки преступления» и «признаки состава преступления», истолковываемые многими авторами в качестве взаимозаменяемых [3, с. 14, 15], несмотря на то, что для подобных умозаключений нет никаких предпосылок. Говоря о признаках преступления, законодатель, надо полагать, адресовал свои установления не только и даже не столько власт- 
ным участникам стадии возбуждения уголовного дела, сколько «рядовым» гражданам (заявителям), не имеющих никакого представления о специальной юридической терминологии и технике. Именно они в своих устных и письменных обращениях форматируют то, что условно можно называть подозрением на уголовно наказуемое деяние, совершенное в отношении того или иного лица (пострадавшего) [8, с. 28, 29].

Среди властных участников стадии возбуждения уголовного дела, полномочных проводить процессуальную проверку, ч. 1 ст. 144 УПК РФ, указывает, прежде всего, дознавателя и орган дознания. Если говорить о дознавателе, то порядок проведения им процессуальной проверки, особых неясностей, как правило, не вызывает. Сложнее - с органом дознания, под которым принято подразумевать, среди прочих, орган внутренних дел (ч. 1 ст. 40 УПК РФ). В данном контексте возникает вопрос, как такой коллективный субъект, главным образом, административных правоотношений может осуществлять процессуальную проверку самостоятельно?

Далее в указанной норме детализируется, что поименованные должностные лица обязаны принять, проверить сообщение о любом совершенном или готовящемся преступлении и в пределах компетенции, установленной УПК РФ, принять по нему решение в срок не позднее 3 суток со дня поступления указанного сообщения [2].

Оценивая подобную редакцию текста закона, желательно учитывать, что уголовно-процессуальные правоотношения начинаются не с момента поступления сообщения о преступлении в дежурную часть органа внутренних дел, а с момента его регистрации в КУСП, что принципиально важно. Суть проблемы состоит в том, что комментируемые законодательные упущения толкают недобросовестных сотрудников органов внутренних дел (полиции), включая дознавателей, на искусственное увеличение процессуальных сроков, нормативно определенных для стадии возбуждения уголовного дела.

При проверке сообщения о преступлении дознаватель и орган дознания уполномочены получать объяснения, образцы для сравнительного исследования, истребовать документы и предметы, изымлать их в порядке, установленном УПК РФ, назначать судебную экспертизу, принимать участие в ее производстве и получать заключение эксперта в разумный срок, производить осмотр места происшествия, документов, предметов, трупов, освидетельствование, требовать производства документальных проверок, ревизий, исследований документов, предметов, тру- пов, привлекать к участию в них специалистов, давать органу дознания обязательное для исполнения письменное поручение о проведении оперативно-розыскных мероприятий.

Приведенные законодательные установления не корректны, поскольку:

- во-первых, ориентируют дознавателей и органы дознания на допустимость производства в рамках процессуальной проверки осмотра места происшествия в любое время, тогда как по смыслу ч. 2 ст. 176 УПК РФ, поименованное следственное действие должно выполняться в порядке исключения в пределах суток до начала предварительного расследования;

- во-вторых, юридически неграмотно выделяют среди прочих проверочных действий не только осмотр места происшествия, но и другие разновидности следственного осмотра';

- в-третьих, допускают выполнение такого проверочного действия, как изъятие, хотя УПК РФ такового не знает, хотя и использует его аналог в тексте других правовых норм (например, в ч. 10 ст. 182 УПК РФ). В числе следственных, но не проверочных, адекватных по технологии действий, легализованных в УПК РФ, известна только выемка (ст. 183);

- наконец, в-четвертых, используют в приложении к процессуальным срокам оценочный термин «разумный», не имеющий для уголовного процесса абсолютно никакого значения.

Таким образом, правовые средства, предоставляемые законодателем сотрудникам органов внутренних дел (полиции) на проведение процессуальных проверок, в федеральном законодательстве урегулированы и бессистемно, и некачественно.

В ч. 1.1 обсуждаемой статьи провозглашается, что лицам, участвующим в процессуальных действиях при проверке сообщения о преступлении, разъясняются ux права и обязанности, предусмотренные УПК РФ, и обеспечивается возможность их осуществления в той части, в которой они (эти права и обязанности), а также принимаемые в связи с ними процессуальные решения, затрагивают их интересы.

Обсуждаемые установления в прикладной плоскости не выполнимы, поскольку правовое положение участников стадии возбуждения уголовного дела (заявителей, лиц, дающих объяснения, очевидцев, граждан, предположительно причастных к преступлению или

' При условии, конечно, что подобный осмотр не охватывается осмотром места происшествия. 
совершивших его, адвокатов и проч.) в УПК РФ урегулировано очень слабо.

Согласно ч. 1.2 комментируемой статьи, полученные в ходе проверки сообщения о преступлении сведения могут быть использованы в качестве доказательств при условии соблюдения положений ст. 75 и 89 УПК РФ. Данные нормативные правовые положения равно не убедительны, поскольку полученные в стадии возбуждения уголовного дела «доказательства» в подавляющем числе случае «перепроверяются» (дублируются) дознавателями (органами дознания) сразу же после начала официального расследования.

К тому же несовершенно содержание ст. 89 УПК РФ, ибо непонятно, как это в ходе оперативно-розыскной деятельности можно получить доказательства, отвечающие требованиям УПК РФ?

Часть 3 ст. 140 УПК РФ гласит, что начальник органа дознания вправе по мотивированному ходатайству дознавателя продлить до 10 суток срок, установленный «частью первой настоящей статьи». При необходимости производства документальных проверок, ревизий, судебных экспертиз, исследований документов, предметов, трупов, а также проведения оперативно-розыскных мероприятий ... прокурор по ходатайству дознавателя вправе продлить этот срок до 30 суток с обязательным указанием фактических обстоятельств, послуживших к тому основанием.

Как видим, согласно указанной норме, никому неведомый начальник органа дознания (его правовое положение в УПК РФ до сих пор не регламентировано) вправе удовлетворить ходатайство дознавателя в части, касающейся продления сроков процессуальной проверки.

Не менее благосклонно к обсуждаемым инициативам дознавателя может относиться и прокурор в обход кропотливого участия в этом вопросе непосредственного начальника упомянутого субъекта доказывания - руководителя подразделения дознания, а также начальника органа дознания.

По состоянию на сегодняшний день порядок взаимодействия дознавателей (органов дознания) с оперативно-розыскными органами более чем подробно, если не сказать чрезмерно, регламентирован УПК РФ, однако, вопросы остаются [6, с. 179-182].

Анализ современного нормативного правового потенциала института дознания, в частности, и УПК РФ в целом, показывает, что парламентарии безмерно увлеклись наполнением его, скажем так, «особыми условиями», императивно рекомендуемыми к соблюдению при выявлении и расследовании преступлений экономической направленности (банковских, налоговых) и даже преступлений, связанных с незаконным оборотом наркотиков.

Подобная законодательная политика, на взгляд автора настоящей статьи, поддержки не заслуживает, поскольку посредством означенных интервенций российское уголовно-процессуальное законодательство теряет свойственный ему универсализм, превращаясь в труднодоступный для понимания, толкования и применения свод иллюзорных правил.

Показательными в этой связи являются положения ч. 7-9 с. 144 УПК РФ, где, к слову заметим, законодатель рассуждает об органах дознания, неудачно смешиваемых им в ч. 1 ст. 40 УПК РФ с органами внутренних дел и с оперативно-розыскными органами. Хотя еще профессор И.М. Гуткин подвергал конструктивной критике излишне широкую трактовку дознания с вовлечением в него оперативно-розыскных мероприятий [5, с. 80].

Серьезно осложняет процессуальную проверку отсутствие у дознавателей (органов дознания) полномочий на истребование в кредитных организациях сведений о движении денежных средств по счетам проверяемых (разрабатываемых) «фигурантов».

В целях умаления негативного влияния указанных обстоятельств на процессуальную деятельность органов дознания и их должностных лиц, а также повышения учетно-регистрационной дисциплины в органах внутренних дел (полиции) целесообразно переработать действующие нормативные правовые акты МВД Российской Федерации в этом направлении.

Требования, поручения и запросы дознавателей, направляемые ими в порядке ч. 4 ст. 21 УПК РФ, обязательны для исполнения всеми учреждениями, предприятиями, организациями, должностными лицами и гражданами. Тем не менее, до сих пор вышеназванные должностные лица органов дознания не обладают прямым доступом к всевозможным оперативно-справочным базам, розыскным и криминалистическим учетам, в результате чего значительную часть их служебного времени занимает бюрократическая переписка, а истребованная информация далеко не всегда отвечает предъявляемым к ней требованиям'.

В условиях нынешнего дня постановка означенной проблемы остаётся весьма актуальной, что обусловливается:

Формируется сотрудниками оперативно-аналитических подразделений в объеме, недостаточном для инициатора. 
- подвижностью оперативно-розыскного и уголовно-процессуального законодательства;

- постоянным реформированием системы правоохранительных органов;

- юридически не выдержанными предписаниями, содержащимися в ведомственных (подзаконных) нормативных правовых актах.

В контексте изложенного значимо то, что органы и подразделения дознания, а также дознаватели должны в полной мере заниматься процессуальными проверками, не требующими активного оперативно-розыскного сопровождения, по всем без исключения сообщениям о подведомственных МВД РФ преступлениях. В этом смысле целесообразно отредактировать ч. 1 ст. 41 УПК РФ, в которой в непривлекательной форме декларируется, что полномочия органа дознания (читай - органа внутренних дел - И.Ф.), предусмотренные п. 1 ч. 2 ст. 40 УПК РФ, возлагаются на дознавателя начальником органа дознания или его заместителем. Получается каламбур: полномочия органа (организации) могут возлагаться на конкретное должностное лицо никому неведомым начальником.

Федеральный закон от 07.02.2011 № 3 «О полиции» [1] вышеназванных противоречий не избежал. Согласно ст. 13 названного Закона, полиции для выполнения возложенных на неё обязанностей предоставляется право:

- производить в случаях и порядке, предусмотренных уголовно-процессуальным законодательством Российской Федерации, следственные и иные процессуальные действия, оперативно-розыскные мероприятия;

- изъятие предметов, документов, материалов и иные предусмотренные федеральным законом действия при осуществлении оперативно-розыскной деятельности;

- объявлять розыск и принимать меры по розыску лии, совершивших преступления или подозреваемых и обвиняемых в их совершении ', лиц, пропавших без вести, иных лиц, розыск которых возложен на полицию, а также объявлять розыск и принимать меры по розыску похищенных или угнанных транспортных средств, похищенного имущества, имущества, подлежащего конфискации.

В силу этого, несовершенство законодательств уголовно-правового блока в части, касающейся регулирования порядка проведения процессуальных проверок, не лучшим образом сказывается на эффективности дея-

\footnotetext{
1 Формулировка «принимать меры по розыску лии, совершивших преступления или подозреваемых и обвиняемых в их совершении» тавтологична.—-прим. авт.
}

тельности органов и подразделений дознания. На данное обстоятельство справедливо указывает профессор Б.Я. Гаврилов, убежденный в том, что досудебное производство в современном его виде остаётся чрезвычайно забюрократизированным и сущностно затратным при его недостаточной эффективности» [4, с. 152-160].

Стереотипная критика практики взаимного административного обособления субъектов оперативно-розыскной и уголовно-процессуальной деятельности при выявлении и расследовании преступлений, достаточно часто встречается на страницах юридической литературы. Однако объективный взгляд на эксплуатацию означенной (псевдо) правовой идеи обнаруживает поразительное сходство взглядов ученых на её антитезу. Квинтэссенцией последней является тезис о том, что совместная, рационально обустроенная деятельность органов дознания и оперативно-розыскных органов значительно повышает её эффективность, в том числе, и особенно, в условиях следственно-оперативных групп [7, с. 116-119], где провозглашаемая и критикуемая разобщенность в прикладной плоскости теряет всяческий смысл.

В теории уголовно-процессуального права неоднократно высказывалось не лишенное оснований мнение о том, что следователи, в принципе, заниматься процессуальными проверками не должны. Их задача, как утверждается, состоит исключительно в расследовании преступлений и только. В методологическом аспекте вопрос очень важный и его радикальное разрешение способно обеспечить стабильность долгосрочного сотрудничества оперативно-розыскных органов и органов дознания в обозримом будущем.

Информационная насыщенность материалов процессуальной проверки предопределяют своевременность и обоснованность возбуждения уголовного дела. Планирование и осуществление сопутствующих обеспечительных мероприятий возлагается, в том числе, на органы дознания; целью первого порядка у них выступает (профилактика), выявление, предупреждение и пресечение преступлений, а целью второго - эффективное, в пределах компетенции, установленной законом, их расследование

Как известно, рассматриваемая стадия уголовного процесса не включается во внутреннюю структуру частных криминалистических методик расследования [9], но от этого её практическая ценность не умаляется. Именно в её рамках формируются «достаточные основания» для принятия дознавателями (органами дознания) юридически грамотных процессуальных и тактических решений, обеспечивается успех предварительного расследования в его завершенном виде. 


\section{ЛИТЕРАТУРА}

1. Федеральный закон от 07.02.2011 № 3 «0 полиции» // Собрание законодательства РФ. 2011. № 7. Ст. 900.

2. Приказ Генеральной прокуратуры Российской Федерации, Министерства внутренних дел Российской Федерации, Министерства Российской Федерации по делам гражданской обороны, чрезвычайным ситуациями ликвидации последствий стихийных бедствий, Министерства юстиции Российской Федерации, Федеральной службы безопасности Российской Федерации, Министерства экономического развития и торговли Российской Федерации, Федеральной службы Российской Федерации по контролю за оборотом наркотиков от 29.12.2005 № 39/1070/1021/253/780/353/399 «0 едином учете преступлений» // СПС Консультант Плюс.

3. Белавин А.А. Процессуальные и организационные аспекты правового положения органов предварительного расследования: автореф. дис... канд. юрид. наук. Красноярск, 2003.

4. Гаврилов Б.Я. 0 соотношении стадии возбуждения уголовного дела и следственной тактики при рассмотрении сообщений о преступлениях // Криминалистическая тактика: современное состояние и перспективы развития: 56-е криминалистические чтения 29 октября 2015 г. М.: Академия управления МВД России, 2015. Ч. 4.

5. Гуткин И.М. Некоторые вопросы теории и практики применения законодательства об органах дознания // Формы досудебного производства и их совершенствование: сборник научных трудов. Волгоград, ВСШ МВД СССР, 1989.

6. Одинцов В.Н. 0 некоторых проблемных вопросах служебной деятельности подразделений дознания // Проблемы расследования нераскрытых преступлений прошлых лет: материалы межвузовского научного семинара 13 ноября 2008 г. М.: Академия управления МВД России, 2008.

7. Савенко Г.Н. Совместные следственно-оперативные группы: проблемы и тенденции // Фундаментальные и прикладные проблемы управления расследованием преступлений: материалы межвузовской научно-практической конференции (к 50-летнему юбилею кафедры управления органами расследования преступлений Академии управления МВД России) 28, 29 апреля 2005 г. М.: Академия управления МВД России, 2005. Ч. III.

8. Ульянова Л.Т. 0 доказывании в стадии возбуждения уголовного дела // Вестник Московского государственного университета. 1971. Серия 11: Право. № 3.

9. Шмонин А.В. Методика расследования преступлений: учебное пособие. М.: Юрлитинформ, 2006.

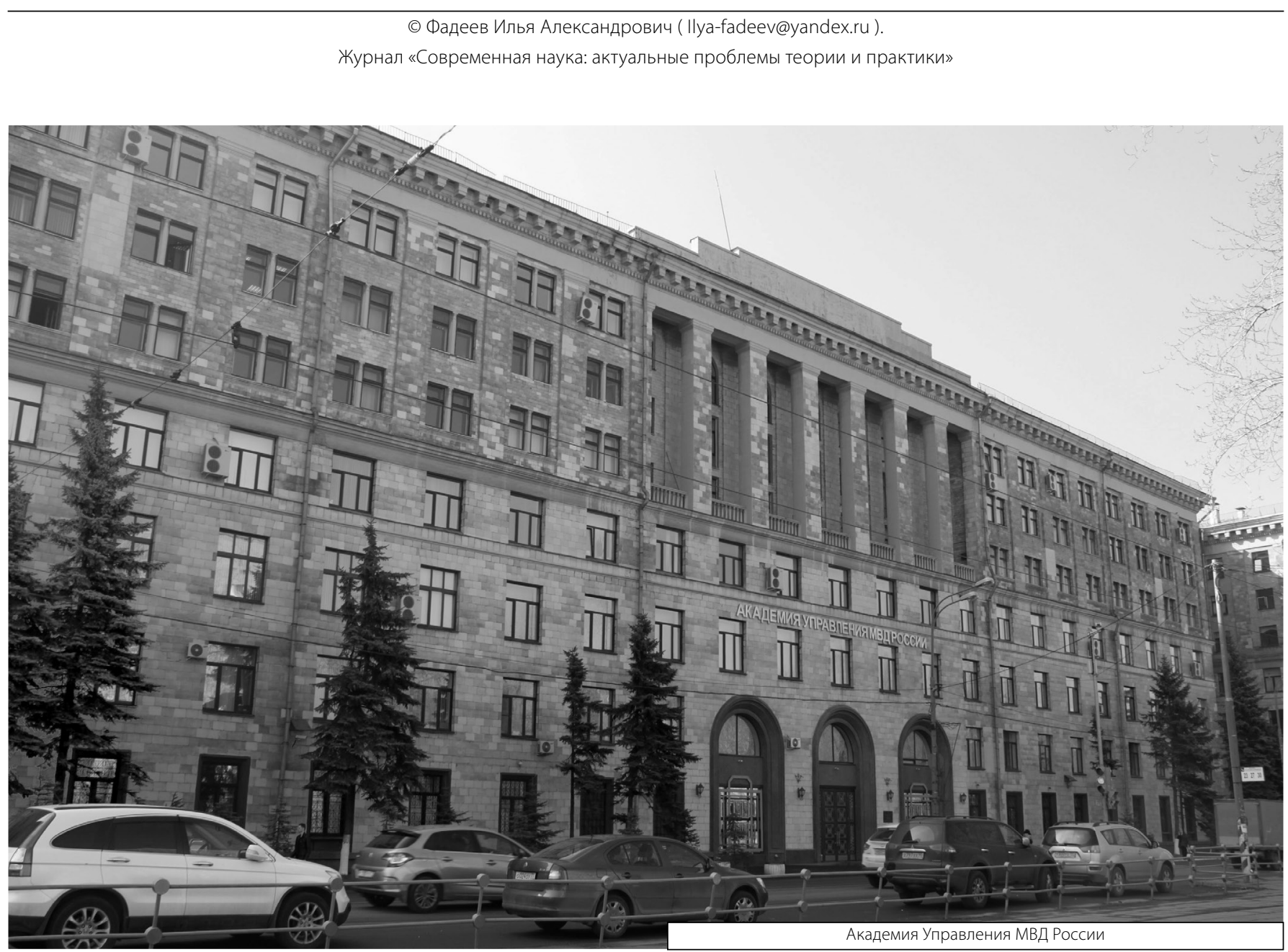

